\title{
URBAN CHANGE DETECTION AND ALERT SYSTEM BASED ON REMOTE SENSINGTECHNIQUESOF SYMBIOSIS UNIVERSITY NAGPUR MAHARASHTRA INDIA.
}

\author{
R R Nagpure ${ }^{1}$ and Sanjay Balamwar ${ }^{2}$ \\ ${ }^{1}$ Dept. of Physics, Sevadal Mahila Mahavidyalaya, Nagpur, M.S., India \\ ${ }^{2}$ Sr. Scientist, Maharashtra Remote Sensing Application Centre, Department of Planning, \\ Govt. of Maharashtra. \\ nagpureraghu@gmail.com
}

Communicated: 14.12 .20

Revision : $19.12 .20 \& 27.12 .2020$

Accepted: 22.01 .2021

Published: 30.01 .2021

\begin{abstract}
:
Remote sensing is the process of detecting and monitoring the physical characteristics of an area by measuring its reflected and emitted radiation at a distance typically from satellite. Special cameras collect remotely sensed images, which help researchers "sense" things about the Earth. For example, Cameras on satellites and airplanes take images of large areas on the Earth's surface, allowing us to see much more than we can standing on the ground. Change detection refers to the process of identifying differences in the state of land features by observing them at different times. This process can be accomplished either manually or with the aid of remote sensing software. change detection refers to the process of identifying differences in the state of land features by observing them at different times. This process can be accomplished either manually or with the aid of remote sensing software. Rapid urbanization has significant impact on resources and urban environment. With increased availability and improved quality of multi-spatial and multi-temporal remote sensing data, it is now possible to detect urban changes in a timely and cost-effective way. This study aims to quantify changes in urban area of Symbiosis University Nagpur Maharashtra India using Land satellite image. Urban changes were detected by satellite images of Land sat MSS in march-2016, march-2018, and may-2020 using a geographic information system (GIS).
\end{abstract}

Key words: - Remote sensing, urban changes, multispectral mode and optical spectrum.

\section{INTRODUCTION:}

Satellite data with high resolution are defined by spatial resolution of about tens of meters. These data are often obtained simultaneously in panchromatic and multispectral mode with significant share of spectral bands covering infrared optical spectrum. Some satellites acquire the data solely in a regular, usually a few weeks period. Other more modern satellites are able to take a data according to the customer's request. In both cases extensive data archives are available containing all the images acquired since the launch of the satellite. Image enhancement is the process of adjusting digital images so that the results are more suitable for display or further image analysis. For example, you can remove noise, sharpen, or brighten an image, making it easier to identify key features. Segmentation is the technique of dividing or partitioning an image into parts, called segments. It is mostly useful for applications like image compression or object recognition This pre-processing includes enhancement using histogram equalization and adaptive histogram equalization of the input image. Post processing is process of editing the data captured by camera while taking the photo to enhance the image. Better the data captured during clicking of photo better is the enhancement possibility. There are more and more camera which have come into market which can capture RAW files.Change detection is a very important 
technique for remote sensing applications. It is the process of identifying changes occurred on the earth surface between the multitemporal images acquired on the same geographical area. Nowadays, the urban expansion is commonly caused by the acceleration of urbanization, it is necessary to detect the changes occurring with urban sprawl. Change detection is an effective means to get the variation information. In recent years, the resolution enhancing of remote sensing image makes it possible to identify detailed changes of urban areas, some challenges are posed to the traditional change detection methods.

\section{MATERIAL \& METHODS:}

Remote sensing technology has many fold applications. The change detection using adequate satellite data with selection of various criteria for identification of positive or negative changes over the period of time this specious temporal data of the same area with different possess over it can be possible to do change detection. In this present study digital image processing techniques of image enhancement, image segmentation, image classification has been used to identify the changes with more accuracy and reliability. In this study area high resolution satellite data of digital globe USA with ward view to sensor with $50 \mathrm{~cm}$ spatial resolution is used. The satellite data of march 2016 is used of analysis using digital image processing techniques similarly analysis of satellite data of the year march 2018 and may 2020 have been analyze and the change detection over the period of 4 years is identified.

\section{Study Area: -}

Nagpur is an interior district of Maharashtrain India with an area of $227.4 \mathrm{Km} 2$ Maharashtra is bounded by the Indian states of Gujarat to the northwest, Madhya Pradesh to the north, Chhattisgarh to the east, Telangana to the southeast, Karnataka to the south, and Goa to the southwest and by the union territory of Dadra and Nagar Haveli and the Arabian Sea to the west. Nagpur district is a district in the Vidarbha region of Maharashtra state in central India. The district lying between latitudes $21^{\circ} 8^{\prime} 47.8788^{\prime \prime} \mathrm{N}$ and longitudes $79^{\circ} 5^{\prime} 19.8960^{\prime \prime} \mathrm{E}$. Study area is extracted from the district map with area covering $77,27,395 \mathbf{~ m}^{2}$.

Here is some good news for hundreds of city students who moved out to Mumbai Pune for higher education to bouts about for long. the India's second biggest symbiosis international university (SIU) will start its operation in 75 acers in Wathoda layout Nagpur Maharashtra India. This university lying between the coordinates latitudes $21^{\circ} \quad 7^{\prime} 41.15^{\prime \prime} \mathrm{N}$ and longitudes $79^{\circ} 9^{\prime} 37.80^{\prime \prime} \mathrm{E}$.

\section{Remote sensing techniques:}

Image Pre-processing is a primary phase of object classification to improve the quality of the image by correcting the unwanted degradation, distortion and various noise in the system. This pre-processing includes enhancement using histogram equalization and adaptive histogram equalization of the input image.

\section{Image Enhancement:}

Satellite image enhancement is the technique which is most widely required in the field of satellite image processing to improve the visualization of the features. Satellite images are captured from a very long distance, so they contain too much noise and distortion because of atmospheric barriers.

\section{Histogram equalization:}

Histogram equalization is a method to process images in order to adjust the contrast of an image by modifying the intensity distribution of the histogram. The objective of this technique is to give a linear trend to the 
cumulative probability function associated to the image.

\section{RESULT \& DISCUSSION:}

\section{Postprocessing:}

Post processing is process of editing the data captured by camera while taking the photo to enhance the image. Better the data captured during clicking of photo better is the enhancement possibility. There are more and more camera which have come into market which can capture RAW files.

\section{Image thresholding:}

Thresholding is a type of image segmentation, where we change the pixels of an image to make the image easier to analyze. In thresholding, we convert an image from color or grayscale into a binary image, i.e., one that is simply black and white.

A simple way to partition of an image is thresholding. It can separate an image into background and closet part. This technique is a type of segmentation technique which first convert gray scale image into binary image and then segments the image. It works effectively on high level of contrast image mostly. The algorithm for image segmentation using thresholding can be applied on gray scale image obtained from the adaptive histogram equalization.$$
\mathrm{G}=\left\{\begin{array}{l}
0, \mathrm{u}<1 \\
1, \mathrm{u} \geq 1
\end{array}\right\}
$$

Where

u- a grey value,

t- a threshold value.

A gray level image can be converted into binary image using appropriate threshold value $t$. the threshold value is the value which has two regions on its either that is below the threshold and above the threshold. The advantages of converting it first in the binary image is that it reduced the short coming of the data and makes it easier to comprehend the process of recollection and classification.

The generalized method to select threshold value is by examining the histogram of the image. There are many others way to find the threshold value like by iterative method and OTSU we developed and algorithm which segments the binary image using the threshold value the pixel value will be compared with the threshold.

\section{CONCLUSION:}

The study concludes that fungal endophyte of Azadirachta indica produces secondary metabolites. Fusarium decemcellulare the isolated endophyte has ability to produce lovastatin. Lovastatin production capacity was determined by HPLC analysis. The inhibitory activity of lovastatin on Sacchromyces cerevisiae depicts its antifungal potential.

\section{Soil of district: -}

There are six types of soils found in Nagpur district. The details are as follows:

1) Kali soils: These are black cotton soils which are fine grained clayey in texture and varies in depth from $1 \mathrm{~m}$ to $6 \mathrm{~m}$ or more and retain moisture. They are found around Kalmeshwar, Saoner and Nagpur.

2) Morand soils: These are predominant in the district. They are black cotton soils with higher percentage of lime than the Kali soils. They are black, grey or light to dark brown in colour, clayey in texture and have a depth of about 1 to $3 \mathrm{~m}$.

3) Khardi soils: They are shallow soils mixed with sand and found mainly in hills. These are grey in colour, clay loam in texture.

4) Bardi soils: They are red gravel covered with boulders found on summits and slopes of trap hills and are less fertile in nature. 
5) Kachchar soils: They are mainly found in the banks of Kanhan river and are alluvial soils, loamy in nature and vary in depth from 1 to $3 \mathrm{~m}$.

6) Wardi soils: They are red soils with a large amount of sand. They are shallower and clayey loam in nature. They are mainly found in the paddy tracts in the eastern part of the district.

\section{Climate of district: -}

The climate of the district is characterized by a hot summer and general dryness throughout the year except during the south-west monsoon season, i.e., June to September. The mean minimum temperature is $12^{\circ} \mathrm{C}$ and mean maximum temperature is more than $45^{\circ} \mathrm{C}$. .

The normal annual rainfall (1901-1992) over the district ranges from about $1000 \mathrm{~mm}$ to $1200 \mathrm{~mm}$. It is the minimum in the western parts around Katol $(985.4 \mathrm{~mm})$ and increases in the eastern direction and reaches a maximum around Umrer (1213.6 mm).

Rainfall data from 14 rain gauge stations for the periods 2002-2011 are given in table 3 . The average annual rainfall for the last 10 years ranges from 753.9 in Hingni to 1164.9 in Umrer.

\section{CONCLUSION:}

It is also observed that all stations have recoded average annual rainfall within the range of district normal annual rainfall except at Hingni, Katol, Narkhed and Kamleshwar where it is less than

\section{REFERENCES:}

Agarwal, C Green, G.M., Grove, J.M., Evans, T.P., and Schweik , C.M. 2002. A review and assessment of land use change models: Dynamics of space, time, and human choice. General Technical Report NE297.Newton square, Pennsylvania, U.S. Department of Agriculture Forest Service, Northeastern Research Sttion.61pp.
INSPIRE Data Specificatin for the spatil data theme Land Cover and Land Cover and Land Use-Technical Guideines. European Commission Joint Research Centre; 2013.

Akbari, H., Shea Rose, L., and Taha, H.2003Analysing and land cover of an urban environment using high-resolution orthophotos. Landscape and Urban Planning, 63,1-44.

Brown, D.G., Page, S., Riolo, R., Zellner, M., and Rand, W.2005.Path dependence and the validation of agent-based spatial models of land use. International journal of Geographical information Science, 19,153174.

Brown, D.G., Goovaerts, P., Burnicki, A., and Li, M.Y.2002. Stochastic simulation of landcover change using geostatistics and generalized additive models .Photogrammetric Engineering and Remote Sensing, 68(10), 1051-1061.

Cots-Folch, R., Aitkenhead, M.J., and MartinezCasasnovas, J.A.2007. Mapping land cover from detailed aerial photography data using textural and neural network analysis. International Journal of Remote Sensing, 28(7), 1625-1642.

Dobson, J.E. Bright, E.A., Coleman, P.R.,Durfee, R.C., and Worley, B.A. 2000.LandScan: A global population database for estimation populations at risk. Photogrammetric Engineering and Remote Sensing,66(7), 849-857.

Elvidge,C.D., Baugh, K.e., Kihn, E.A., Kroehl, H.W., and Davis, R.R. 1997. Mapping city lights with night-time data from the DMSP operational Linescan System. Photogrammetric Engineering and Remote Sensing, 57(110), 1453-1463.

Chowdhury, R.R.2006. Driving forces of tropical deforestation: The role of remote sensing 
and spiral models. Singapore Journal of Tropical Geography,27, 82-101.

Bong, D.B.1., Lai, K.C.and loseph, A.2009.Automatic road network recognition and extraction for urban planning .International Journal of Engineering and Applied sciences, 5,54-59.
Chen, H. and Pontius, Jr., R.G.2010.Diagnostic tools to evaluate a spatial land change projection along a gradient of an explanatory variable .Landscape Ecology, 22,1383-1393.

Fig a showing the details of analysis and area under change of march-2016.

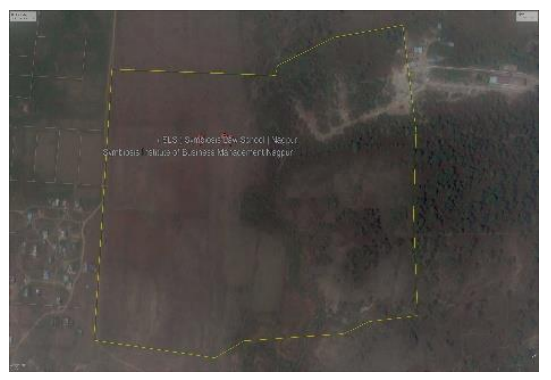

Satellite data of march- 2016

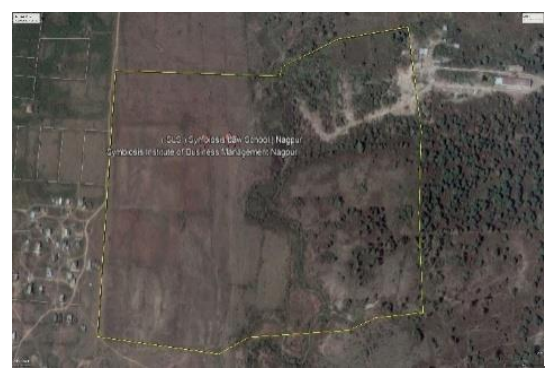

Image enhancement

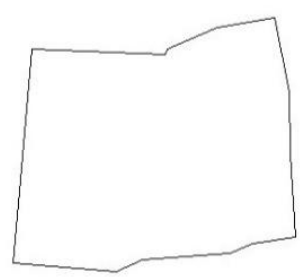

Image segmentation

\begin{tabular}{|l|l|l|l|}
\hline Sr. No. & Land used class & Area $\mathbf{~ m}^{\mathbf{2}}$ & Percent \% \\
\hline 1 & Open Plot & $7727395 \mathrm{~m}^{2}$ & $100 \%$ \\
\hline
\end{tabular}

Fig a showing the details of analysis and area under change of march-2018.

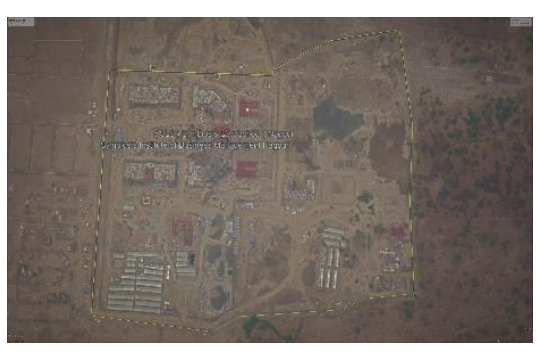

Satellite data of march- 2018

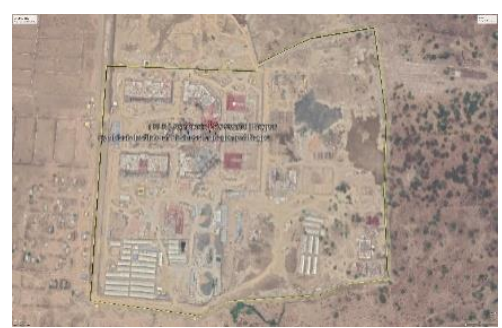

Image enhancement

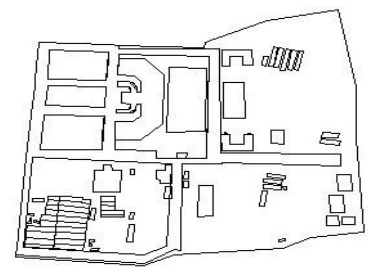

Image segmentation

\begin{tabular}{|c|c|c|c|}
\hline Sr. No. & Land used class & Area m & Percent \% \\
\hline 1 & Building & 1331835 & $17.35 \%$ \\
\hline 2 & Road & 1330762 & $17.22 \%$ \\
\hline 3 & Garden & 129382 & $1.67 \%$ \\
\hline 4 & Containers & 490434 & $6.34 \%$ \\
\hline 5 & Open space & 4444964 & $57.52 \%$ \\
\hline 6 & Total plot & 7727395 & $100 \%$ \\
\hline
\end{tabular}


Fig a showing the details of analysis and area under change of May-2020.
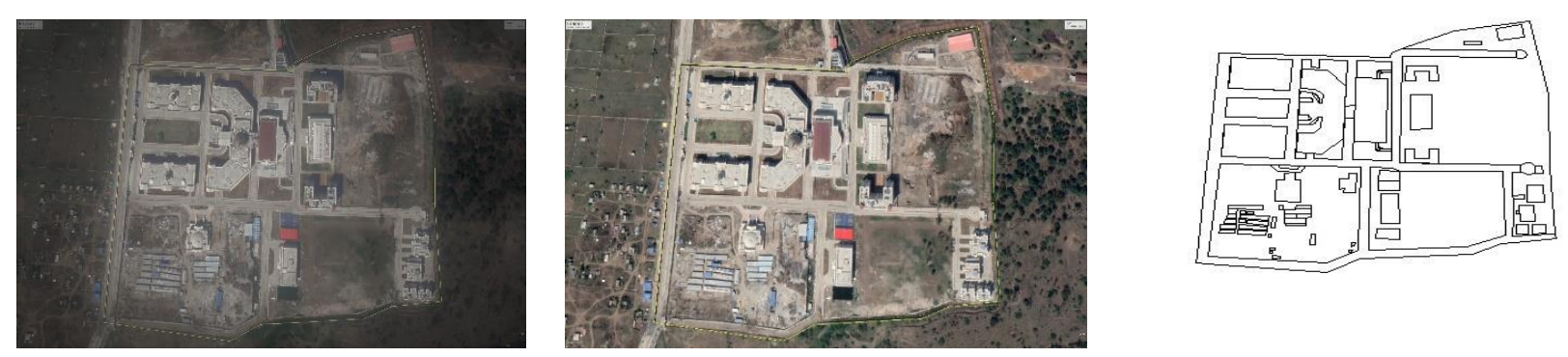

Satellite data of May- 2020

Image enhancement

Image segmentation

\begin{tabular}{|c|l|c|c|}
\hline $\begin{array}{c}\text { Sr. } \\
\text { No. }\end{array}$ & \multicolumn{1}{|c|}{ Land used class } & Area $\mathbf{~ m}^{\mathbf{2}}$ & Percent \% \\
\hline 1 & Building & 1340905 & $17.35 \%$ \\
\hline 2 & Road & 1600354 & $20.71 \%$ \\
\hline 3 & Garden & 128161 & $1.65 \%$ \\
\hline 4 & Ground & 68997 & $0.89 \%$ \\
\hline 5 & Containers & 223427 & $2.89 \%$ \\
\hline 6 & Open space & 4365651 & $56.49 \%$ \\
\hline 7 & Total plot & 7727395 & $100 \%$ \\
\hline
\end{tabular}
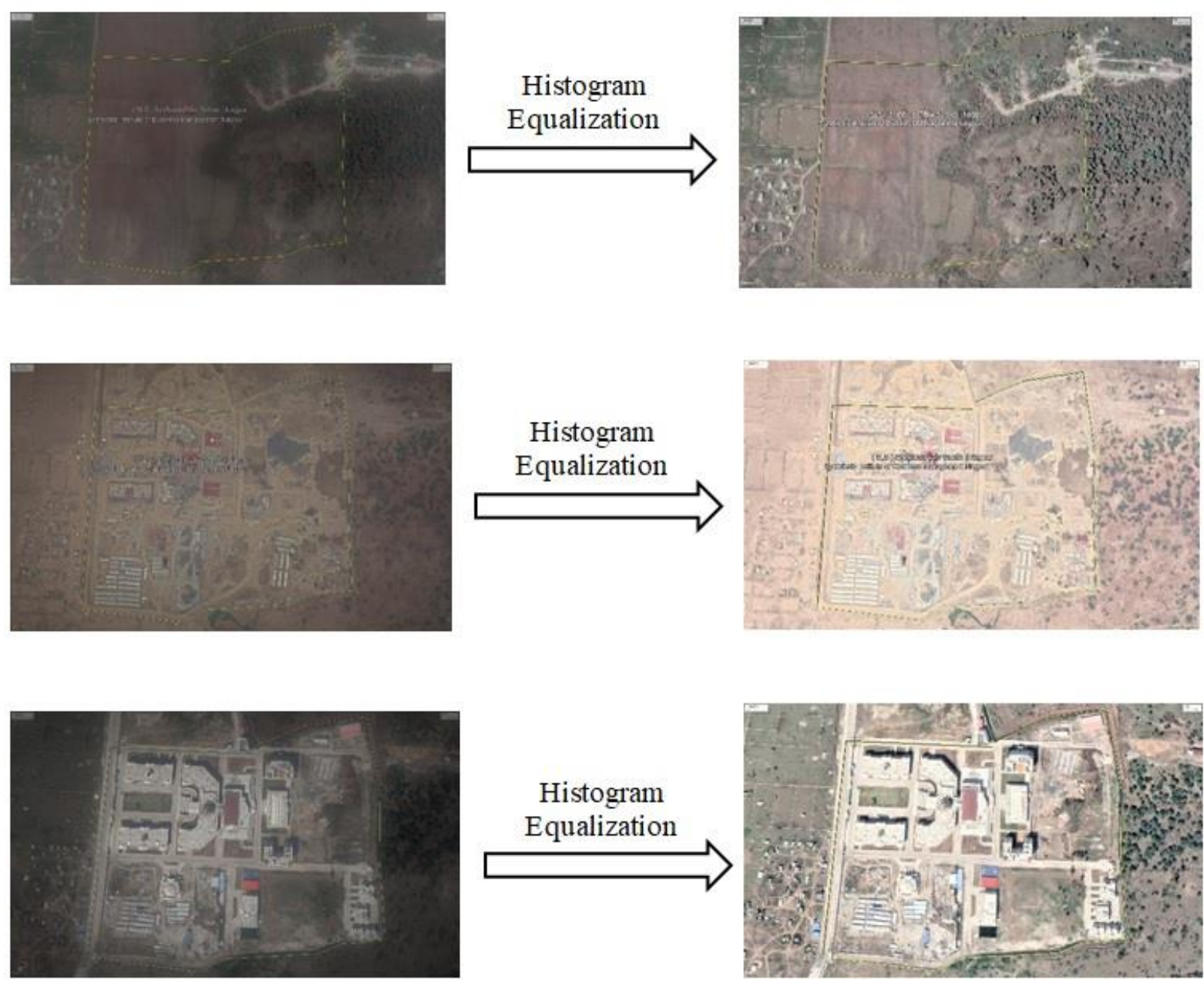

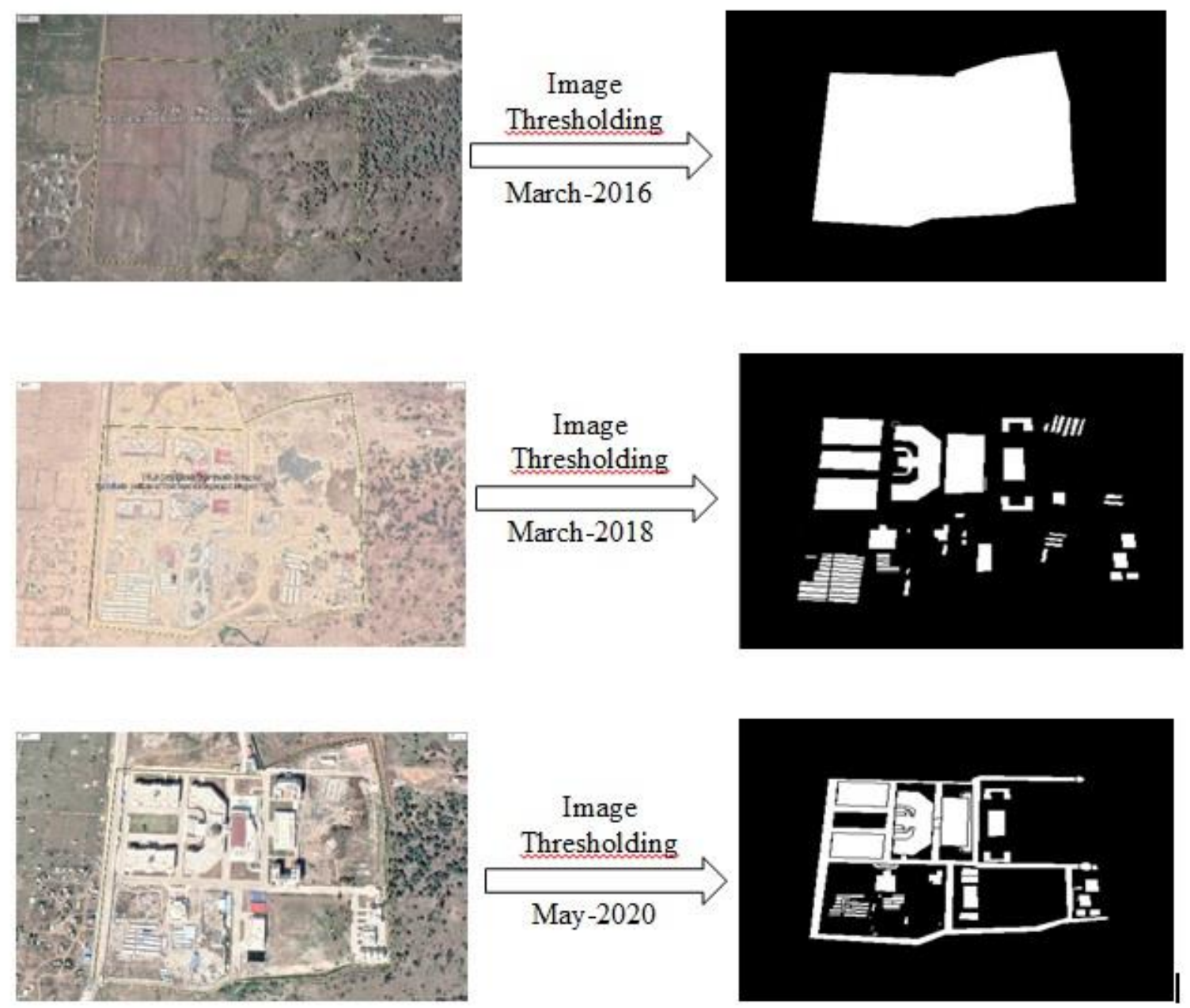